\title{
TEM Study of Nanoprecipitation and Dislocation Interactions in Novel Cold Rolled "Nano-Steel"
}

Angelos Kaldellis ${ }^{1}$, Nikolaos Makris ${ }^{2}$, Petros Tsakiridis ${ }^{1}$ and George Fourlaris ${ }^{1}$

${ }^{1}$ Lab. of Physical Metallurgy and Center for Electron Microscopy, School of Mining and Metallurgical Engineering, National Technical University of Athens, 15780 Athens, Greece., United States, ${ }^{2}$ Lab. of Physical Metallurgy and Center for Electron Microscopy, School of Mining and Metallurgical Engineering, National Technical University of Athens, 15780 Athens, Greece, Athens, Acharnes, Greece

Over several years, automotive and steel-making industries have continuously conducted research to reduce fuel consumption, $\mathrm{CO} 2$ emissions, cost production, raw material and steel consumption. Nanosteels strips, developed for light-weight automotive applications, are a new generation of Advanced High Strength Steels (AHSS), developed to meet these demands. These modern steel grades can contribute a combination of high strength, ductility and improved complex formability performance [1]. Their characteristics stem from a suitable micro-alloying design and thermomechanical controlled processing (TCMP) that produce an essentially soft single-phase ferritic matrix strengthened by second-phase nanoprecipitates $[1,2]$.

The most common additions of micro-alloying elements are Vanadium (V), Niobium (Nb), Molybdenum (Mo) and Titanium (Ti) that improve the precipitation hardening mechanisms of nano-steels by the formation of carbides (MXCY), nitrides (MXNY) and carbonitrides (MX,(CY,N1-Y)) in nano-scale [1, 2]. Optimized TCMP routes of nano-steels strips are employed in the reheating, finishing rolling and coiling stages, coupled with suitable micro-alloying additions, to produce fine nano-precipitation to strengthen the ferritic matrix. Important parameters to consider are the control of austenite grain growth via a second phase pinning effect, delayed recrystallization of the deformed austenite, and improved ferritic grain refinement coupled with enhanced precipitation hardening [3]. These parameters affect nucleation and growth phenomena, as well as the developing orientation relationship (Baker-Nutting (B$\mathrm{N}$ ) in ferrite and Kurdjumov-Sachs (K-S) in austenite, of some nano-precipitates [4].

In this research, cold-rolled micro-alloyed single-phase $\mathrm{V}$ and $\mathrm{Nb}$-bearing ferritic strip steels are studied to follow and fully characterize nano-precipitates evolution, as well as their interaction with dislocations and matrix. This investigation, confirmed the presence of fine $(<100 \mathrm{~nm})$ and ultra-fine $(<10 \mathrm{~nm})$ precipitations predominantly rich in both $\mathrm{V}$ and $\mathrm{Nb}$ (as indicated by TEM-EDS examination), as well as their interplay with the most representative dislocations structures (tangles and walls). The majority of nano-precipitates examined, appear as fine-dispersed and mixed formation within ferritic grains and on grain boundaries; in particular, it is observed that very-fine $(<10 \mathrm{~nm})$ circular and fibrous nanoprecipitates (fig. 1a) and relative larger $(<100 \mathrm{~nm}$ ) (fig. 1b) rich in $\mathrm{V}$ and $\mathrm{Nb}$. The type of formation is characterized as mixed, due to the observed predominantly random (fig. 2a) and rarely interphase precipitates (fig. 2b). It can be noticed that interphase formation of precipitates develops with close compliance to the B-N orientation relationship in ferrite and the mean interprecipitate spacing is estimated to be $26 \mathrm{~nm}$ approximately (fig. 2b). Moreover, disparate in size precipitates are formed during different stages of TCMP; thus, larger precipitates are responsible for austenitic grain refinement via pinning effect in hot-rolling passes and smaller-size precipitates mainly improve the precipitation strengthening sequences $[4,5]$. 

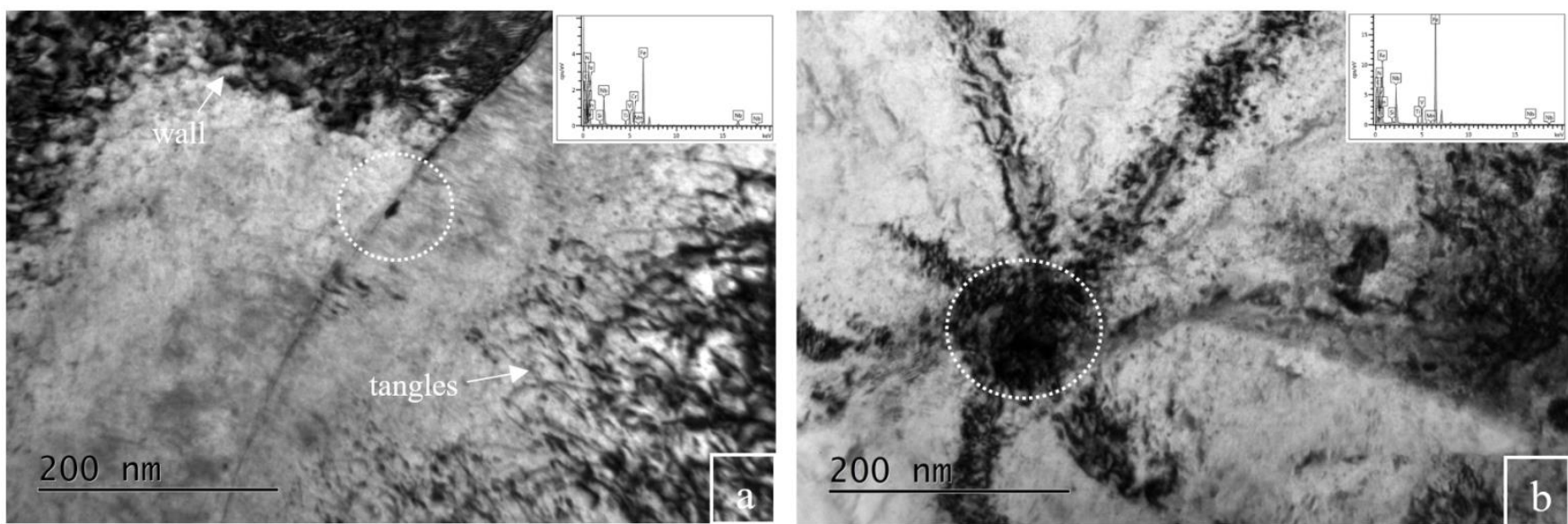

Figure 1. BF TEM micrographs and TEM-EDS spectrums: a) region of ferrite grain boundary, showing most representative dislocations structures (tangles and walls) and their interaction with nano-precipitates, b) site of large nano-precipitate, presenting the dislocation interaction with large and fine nano-precipitates. White dashed circles show TEM-EDS examination areas, predominantly rich in both $\mathrm{V}$ and $\mathrm{Nb}$.
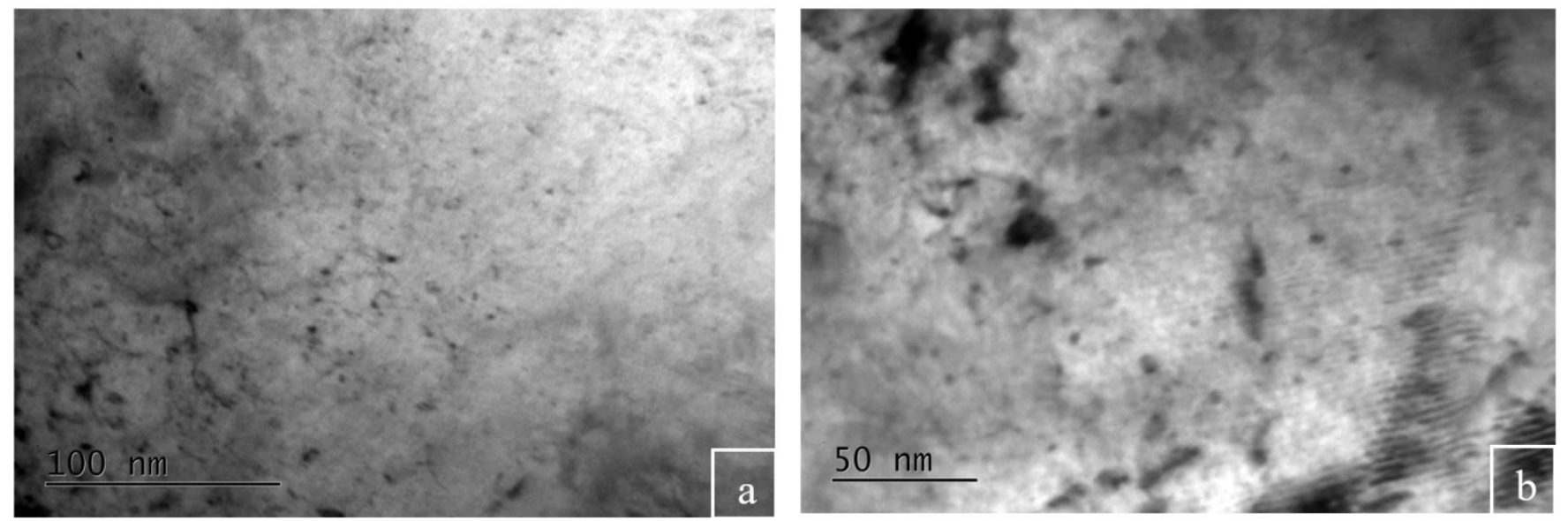

Figure 2. BF TEM micrographs that present mixed (mainly random in 2a, or rarely interphase in 2b) ultra-fine nano-precipitates.

\section{References}

[1] Rijkenberg, A., et al: (2014). Advanced High Stretch-Flange Formability Steels for Chassis \& Suspension Applications, SCT2014, pp. $426-433$.

[2] Zaitsev, A. I., et al: (2020). Study of Features of Phase Precipitate Formation, Structural State, and Properties of Nb, V-Microalloyed Low Carbon Ferritic Steels, Metallurgist, 63, 1033-1042. https://doi.org/10.1007/s11015-020-00922-z.

[3] Nishioka, K. and Ichikawa, K.: (2012). Progress in thermomechanical control of steel plates and their commercialization, Science and Technology of Advanced Materials, 13 (2), 023991, doi: 10.1088/14686996/13/2/023001.

[4] Baker, T. N.: (2009). Processes, microstructure and properties of vanadium microalloyed steels, Mat. Sc. \&Techn., 25 (9), pp. $1083-1107$.

[5] Deligiannis, S., et al: (2018). TEM Study of Nanoprecipitate Formation in Novel HSLA Steels, M\&M 2018, 24 (1), 2230, doi:10.1017/S1431927618011637. 